\title{
Evaluating Mindfulness Meditation Apps
}

Claudia Daudén Roquet

Lancaster University

Lancaster, UK

c.daudenroquet1@lancaster.ac.uk

\section{Corina Sas}

Lancaster University

Lancaster, UK

c.sas@lancaster.ac.uk
Permission to make digital or hard copies of part or all of this work for personal or classroom use is granted without fee provided that copies are not made or distributed for profit or commercial advantage and that copies bear this notice and the full citation on the first page. Copyrights for third-party components of this work must be honored. For all other uses, contact the owner/author(s).

Copyright is held by the author/owner(s).

CHI'18 Extended Abstracts, April 21-26, 2018, Montréal, QC, Canada.

ACM ISBN 978-1-4503-5621-3/18/04.

https://doi.org/10.1145/3170427.3188616

\begin{abstract}
Mindfulness meditation has significant benefits for health and well-being but requires training. A wealth of mindfulness meditation apps have been developed in the last years. However, there has been limited academic work evaluating these technologies. This paper reports an auto-ethnographic and expert evaluation study of 16 most popular iPhone mindfulness apps in the UK. Findings indicate that these apps focus mostly on guided meditation, with limited support for monitoring intrinsic meditation processes and

measuring the effectiveness of the training. We propose a more nuanced discourse around such apps concluding with implications for design; including new tools for supporting intrinsic meditation processes and bodily kinetic aspects fostering mindfulness, together with the call for developing guidelines for evaluating the effectiveness of such applications.
\end{abstract}

\section{Author Keywords}

Mindfulness; meditation; mental health; mobile apps.

\section{ACM Classification Keywords}

H.5.m. Information interfaces and presentation (e.g., $\mathrm{HCI}$ ): Miscellaneous. 


\section{Introduction}

Very often we rush through life without noticing, resulting in stress as well as physical and mental health issues. Mindfulness has been defined as the awareness that arises through paying attention on purpose, in the present moment without judgment [1]. While this practice has shown significant benefits for health and well-being, and especially for stress reduction and depression [8], the term mindfulness usually covers a family of self-regulation techniques e.g. sitting meditation, movement meditation (yoga or tai-chi), or breathing and visualization exercises. A landmark work for categorizing such techniques has been proposed by Nash and Newberg based on neuroscience findings [7]. This paper draws from HCI and commercial work on mindfulness and mindfulness-based applications (MBAs), which have the potential of offering alternative delivery medium and of fostering adoption of meditation practice in everyday life. There has been however limited investigation of the specific meditation techniques addressed in MBAs, which limits our understanding of their effectiveness. To address this gap, we explored the meditation techniques underpinning the most popular iPhone MBAs in the UK. Although these apps represent a small portion over all MBAs available, our work aims to encourage a more nuanced discourse of MBAs and their relative effectiveness. With findings from an auto-ethnographic and expert evaluation of the apps, we then discuss implications for design [13] including bodily aspects to mindfulness meditation and a call for developing a framework for evaluating MBAs.

\section{Mindfulness-Based Applications}

The prevailing attention on mindfulness and the accessibility of mobile applications in daily life has increased the amount of MBAs. Recent findings indicate their effectiveness on stress reduction $[3,4]$, and improving well-being [5]. For example, a recent evaluation of MBAs has shown that only $4 \%$ provide mindfulness training, while the majority mostly offer time reminders for meditation [6]. This work however only explores the general qualities of MBAs (i.e. user interface, functionalities) providing limited insights into their design informed by mindfulness meditation literature. HCI scholars have also developed interactive technologies to support mindfulness training. Findings indicate the value of integrating wearables [11] and virtual reality $[14,17]$ in enhancing self-awareness and self-regulation of attention, which are two of the main processes involved in mindfulness meditation [10].

To conclude, mindfulness-based applications create new opportunities to target wider audiences and to expand their contexts of use. An outstanding challenge is understanding their underpinning techniques and design guidelines for more efficient mindfulness training and compelling user experience.

\section{Methods}

The apps were identified by performing a search of free mindfulness-based meditation applications on the UK iTunes app store. The search included keywords such as mindfulness, meditation, mindful, and well-being. From the 280 apps initially identified, only the ones mentioned in the Health and Fitness category were retained. 


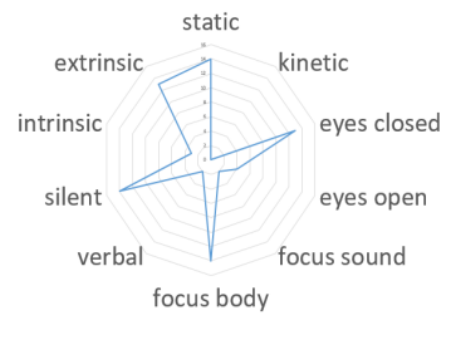

Figure 1: This graph indicates that most MBAs train sitting voice-guided meditation with the eyes closed (Table 1 ). Only two apps focus on sound and two support an internal verbal process, while the rest are silent target the attention to the body experiences.
From these, we selected those with more than 100 ratings in the iTunes app store, and an average rating higher than 3 on a 5 point scale. With the exception of Meditation Timer and 3 Minute Mindfulness apps, the other 14 apps are also available for Android OS. The final 16 apps (Table 1) were evaluated through both an auto-ethnographic approach and expert evaluation study. For the former, all apps have been used by the first author on an iPhone $6 \mathrm{~S}$ for at least 30 minutes including several meditation sessions in a real-world setting. For the expert evaluation, we started by using the Nielsen's heuristics and MARS scale [15]. However, given that the findings were quite generic focusing mostly on the usability of the interface rather than on the training content, we employed the meditation taxonomy proposed by Nash and Newberg [7] grounded in neural correlates of different techniques [16] and their underlying mechanisms [2]. The key dimensions of this taxonomy include: specific cognitive strategies (i.e. focused attention, concentration); object(s) of attention (i.e., conceptual and/or physical foci); description of required beliefs; as well as bodily aspects such as eyes are closed or open during meditation; the process is static (stationary but not necessarily immobile) or kinetic (prescribed movements); a specific body poster is suggested; recommendations for breathing; meditation is silent or auditory, which includes inner speech; the process is intrinsic (self-reliant) or extrinsic (dependent on an outside person or process).

\section{Results}

Findings indicate that there is a lack of diversity on the techniques offered by MBAs (Figure 1), as well as in the context they are employed.

\section{Two Main Classes of MBA}

An important finding is the prevalence of MBAs supporting guided meditation echoing [6]. Furthermore, we found that such apps focus on extrinsic and static processes, leveraging audio output. In contrast, we identified only a small number of apps that relied on intrinsic processes with limited external stimuli (such as Insight Timer, Meditation Timer, and Tide apps). In these cases, the user had no audio guidance but merely a bell sound announcing the start and end of the meditation session. This outcome is surprising, as consistent findings have shown the effectiveness of intrinsic processes in meditation practice [1], indicating a less explored design space.

\section{Bodily Aspects of Mindfulness Meditation}

With a few exceptions (Insight Timer, Digipill, Meditation Timer and Tide app), the majority of apps ask users to focus their attention on their body (Figure 1). In particular, guided meditation apps commonly start with breathing exercises in which users have to focus on feeling how "the air enters the lungs and expands the belly". Calm and 10\% Happier apps use a technique for sustaining attention by counting the breaths, i.e. noting. Other cognitive strategies often prescribed were passive observation and conscious awareness, as shown in the third column of Table 1 . For instance, Headspace app asks to "do not worry about achieving anything, just sit back and enjoy being present in the world". Four apps (Mindfulness Daily, $10 \%$ Happier, Simple Habit, and Pacifica) let the user choose whether to keep the eyes open, but the general recommendation is to keep them closed. While visualization, compassion and imagination are less employed approaches, when used they also focused on the body feeling experienced during meditation. 


\begin{tabular}{|c|c|c|c|c|c|c|c|c|c|c|c|}
\hline App Name & Meditation Type & Cognitive Strategies & $\begin{array}{l}\text { Objects of } \\
\text { attention }\end{array}$ & $\begin{array}{l}\text { Closed / } \\
\text { open eyes }\end{array}$ & $\begin{array}{l}\text { Static/ } \\
\text { kinetic }\end{array}$ & $\begin{array}{l}\text { Verbal / non- } \\
\text { verbal }\end{array}$ & $\begin{array}{l}\text { Intrinsic/ } \\
\text { extrinsic }\end{array}$ & Body Posture & Control of breathing & $\begin{array}{c}\text { Avg } \\
\text { Duration }\end{array}$ & $\begin{array}{c}\text { Sound } \\
\text { Landscape }\end{array}$ \\
\hline Headspace & Guided Meditation & $\begin{array}{l}\text { Focused attention, } \\
\text { Introspection }\end{array}$ & Body & Closed & Static & Non-verbal & Extrinsic & Sitting on a chair & $\begin{array}{l}\text { In nose, out mouth. Focus } \\
\text { on rhythm. }\end{array}$ & $10 \mathrm{~min}$ & none \\
\hline Calm & Guided Meditation & $\begin{array}{c}\text { Concentration, Introspection, } \\
\text { Noting }\end{array}$ & Body & Closed & Static & Verbal & Extrinsic & $\begin{array}{l}\text { Sitting on a cushion } \\
\text { or chair }\end{array}$ & $\begin{array}{l}\text { Gentle breathing. Count } \\
\text { breaths. }\end{array}$ & $\begin{array}{c}3 \min -10 \\
\min \end{array}$ & nature \\
\hline Relax Meditation & Guided Meditation & $\begin{array}{l}\text { Focused attention, } \\
\text { Introspection }\end{array}$ & Body & Closed & Static & Non-verbal & Extrinsic & Sitting on a chair & $\begin{array}{l}\text { In nose, out mouth. Expand } \\
\text { belly. }\end{array}$ & $10 \mathrm{~min}$ & none \\
\hline Insight Timer & $\begin{array}{l}\text { Self-reliant } \\
\text { Meditation }\end{array}$ & Concentration & Sound & - & Static & Non-verbal & Intrinsic & - & - & $5 \mathrm{~min}$ & kangse bell \\
\hline Digipill & Guided Meditation & $\begin{array}{l}\text { Introspection, Passive } \\
\text { observation }\end{array}$ & $\begin{array}{l}\text { Body, } \\
\text { Sound }\end{array}$ & Closed & Static & Non-verbal & Extrinsic & - & - & $13 \mathrm{~min}$ & white noise \\
\hline $\begin{array}{l}\text { Relax with Andrew } \\
\text { Johnson Free }\end{array}$ & Guided Meditation & $\begin{array}{l}\text { Conscious awareness, } \\
\text { Introspection, Body scan }\end{array}$ & Body & Closed & Static & Non-verbal & Extrinsic & Sitting on a chair & Deep breathing & $14 \mathrm{~min}$ & music \\
\hline Mindfulness Daily & Guided Meditation & $\begin{array}{l}\text { Introspection, Focused } \\
\text { attention }\end{array}$ & Body & Any & Static & Non-verbal & Extrinsic & $\begin{array}{l}\text { Sitting, hands on } \\
\text { stomach }\end{array}$ & $\begin{array}{l}\text { Breath in deeply, exhale } \\
\text { slowly }\end{array}$ & $5 \mathrm{~min}$ & none \\
\hline $10 \%$ Happier & Guided Meditation & $\begin{array}{l}\text { Passive observation, } \\
\text { Introspection, Noting }\end{array}$ & Body & Any & Static & Verbal & Extrinsic & Sitting still & $\begin{array}{l}\text { Inhale straigthen the spine, } \\
\text { exhale soften the body }\end{array}$ & $10 \mathrm{~min}$ & none \\
\hline Simple Habit & Guided Meditation & Passive observation & Body & Any & Static & Non-verbal & Extrinsic & $\begin{array}{l}\text { Sitting on a chair or } \\
\text { laying on the ground }\end{array}$ & $\begin{array}{l}\text { In nose, out mouth. Make } \\
\text { outbreath sound. }\end{array}$ & $5 \mathrm{~min}$ & none \\
\hline Omvana & Guided Meditation & $\begin{array}{l}\text { Focus on the self, } \\
\text { Visualization, Body scan }\end{array}$ & Body & Closed & Static & Non-verbal & Extrinsic & Sitting & Deep breathing & $8 \mathrm{~min}$ & none \\
\hline The Mindfulness App & Guided Meditation & $\begin{array}{l}\text { Passive observation, } \\
\text { Intronspection, Compassion }\end{array}$ & Body & Closed & Static & Non-verbal & Extrinsic & $\begin{array}{l}\text { Posture that reflects } \\
\text { dignity. }\end{array}$ & $\begin{array}{l}\text { Expand breathing in, back to } \\
\text { center breathing out }\end{array}$ & $10 \mathrm{~min}$ & none \\
\hline $\begin{array}{l}\text { Pacifica for Stress \& } \\
\text { Anxiety }\end{array}$ & Guided Meditation & $\begin{array}{l}\text { Focused attention, } \\
\text { Intronspection, Imagination }\end{array}$ & Body & Any & Static & Non-verbal & Extrinsic & $\begin{array}{l}\text { Sitting on a cushion } \\
\text { or chair }\end{array}$ & Breathing into stomach. & $9 \min$ & nature \\
\hline Meditation Timer & $\begin{array}{l}\text { Self-reliant } \\
\text { Meditation }\end{array}$ & - & - & - & - & - & Intrinsic & - & - & $10 \mathrm{~min}$ & bell \\
\hline Breethe & Guided Meditation & Focused attention & Body & Closed & Static & Non-verbal & Extrinsic & Sitting on a chair & $\begin{array}{l}\text { Deep breathing. In nose, out } \\
\text { mouth. }\end{array}$ & $10 \mathrm{~min}$ & noise \\
\hline 3 Minute Mindfulness & Guided Meditation & $\begin{array}{l}\text { Focused attention, } \\
\text { Intronspection, Self- } \\
\text { awareness }\end{array}$ & Body & Closed & Static & Non-verbal & Extrinsic & Comfortable position & $\begin{array}{l}\text { Deep breathing. In nose, out } \\
\text { mouth. }\end{array}$ & $3 \mathrm{~min}$ & none \\
\hline $\begin{array}{l}\text { Tide: Focus, Relax, } \\
\text { Meditation }\end{array}$ & $\begin{array}{l}\text { Self-reliant } \\
\text { Meditation }\end{array}$ & - & - & - & - & - & Intrinsic & - & - & $25 \mathrm{~min}$ & nature \\
\hline
\end{tabular}

Table 1: Summary of the meditation techniques used in the evaluated MBAs, based on meditation taxonomic keys [7].

\section{The Context of Mindfulness Meditation}

The majority of the identified applications recommend meditating daily for about 10 minutes, in a quiet place while sitting still and comfortably on a chair or cushion (as shown in Table 1). Relax Meditation app specifically suggests to practice always at the same time in the same calm and private space. While the voice and pace of the delivery of guided meditation vary across apps, there is a gender balance in the meditation instructors.
With respect to the sound landscape, Calm, Pacifica and Tide apps provide nature-inspired sounds; Relax with Andrew Johnson app has music, while Digipill and Breethe apps have white noise. Nonetheless, most MBAs only have the voice of the teacher guiding the meditation, which allows focusing on the surrounding sounds and present experiences. 
Monitoring the Meditation Practice

While a few MBAs allow sharing messages on social media (Headspace, The Mindfulness apps) about the mindfulness experience, a general understanding of the meditation practice is less supported. Despite their popularity, the evaluated MBAs provide limited mindfulness education. The only exception is Headspace app, which supplies video infographics to explain mindfulness concepts in simple terms such as "watching thoughts pass by, without attaching to them". In addition, the effectiveness of each meditation experience is also difficult to evaluate with MBAs. During meditation sessions, they give general messages such as "when your mind wanders, bring it back gently", instead of feedback based on one's performance. Moreover, MBAs do not provide tools to measure the performance neither during meditation nor afterwards.

\section{Design Implications}

Beyond Guided Meditation: Supporting Intrinsic Processes Findings indicate the prevalence of MBAs for guided meditation, which is a less effective technique in terms of health benefits as it supports relaxation rather than mindfulness per se [1]. Designing for intrinsic processes is withal difficult, and mobile technologies with their audio or visual output may pose more challenges for supporting them. This offers up an exciting new design space for undesigning [9] for intrinsic processes, arguably by leveraging other technologies such as tangible interfaces.

New Tangible Interfaces for Supporting Bodily Aspects While the body plays an important role in mindfulness meditation by being the object of attention, it tends to be limitedly accounting for in interface design and UX.
Traditional meditation techniques often employ tools such as baoding meditation balls or the Tibetan wheel for supporting slow and continuous movements fostering mindfulness state. Yet all evaluated MBAs involve static rather than kinetic processes. To address this limitation, we can think of new design opportunities such as novel tangible interfaces augmenting MBAs to support movement. Bodily aspects have been also suggested important in supporting well-being during grief [12]

Developing Guidelines to Evaluate MBAs' Effectiveness A striking finding was that only Headspace app was evidence-based [5]. We did not find reference to the evaluation of health benefits for the other MBAs. We argue for the importance of developing a framework for evaluating the effectiveness of such apps, so that users can make informed choices based on their

effectiveness. This can inform policy makers such as current efforts of the UK National Institute for health and Care Excellence (NICE) for developing an evidencebased system for evaluating health apps.

\section{Conclusions}

This paper evaluates how mindfulness-based applications train mindfulness meditation. Findings indicate that the most popular MBAs focus mostly on guided meditation, while providing limited support for monitoring the intrinsic meditation processes or for measuring the effectiveness of the training. We conclude with implications for design to addressing these limitations through novel tools supporting intrinsic meditation processes and bodily kinetic aspects fostering mindfulness, together with the call for developing guidelines for evaluating the effectiveness of such applications. 


\section{Acknowledgements}

This work has been supported by AffecTech: Personal Technologies for Affective Health, Innovative Training Network funded by the H2020 People Programme under Marie Skłodowska-Curie GA No 722022.

\section{References}

1. Ruth A. Baer. 2003. Mindfulness training as a clinical intervention: A conceptual and empirical review.

Clinical Psychology: Science and Practice 10, 125-143.

2. Amanda E. Berman and Larry Stevens. 2015. EEG manifestations of nondual experiences in meditators. Consciousness and Cognition 31: 1-11.

3. Claudia Carissoli, Daniela Villani, and Giuseppe Riva. 2015. Does a Meditation Protocol Supported by a Mobile Application Help People Reduce Stress? Cyberpsychology, Behavior, and Social Networking 18, 1: 46-53.

4. Luca Chittaro and Andrea Vianello. 2016. Evaluation of a mobile mindfulness app distributed through on-line stores: A 4-week study. International Journal of Human Computer Studies 86: 63-80.

5. Annika Howells, Itai Ivtzan, and Francisco Jose EiroaOrosa. 2016. Putting the "app" in Happiness. Journal of Happiness Studies 17, 1: 163-185.

6. Madhavan Mani, David J Kavanagh, Leanne Hides, and Stoyan R Stoyanov. 2015. Review and Evaluation of Mindfulness-Based iPhone Apps. JMIR mHealth and uHealth 3, 3: e82.

7. Jonathan D Nash and Andrew Newberg. 2013. Toward a unifying taxonomy and definition for meditation. Frontiers in psychology 4: 806.

8. NHS.UK. Mindfulness. Retrieved January 12, 2018 from https://www.nhs.uk/conditions/stress-anxiety- depression/mindfulness/

9. James Pierce. 2012. Undesigning technology: Considering the negation of design by design. Proc. Conference on Human Factors in Computing Systems, 957-966.

10. Corina Sas. 2007. Being Present - Being Mindful Conceptual delimitations and comparative analysis. Proceedings of Peach Summer School.

11. Corina Sas and Rohit Chopra. 2015. MeditAid: a wearable adaptive neurofeedback-based system for training mindfulness state. Personal and Ubiquitous Computing 19, 7: 1169-1182.

12. Corina Sas and Alina Coman. 2016. Designing personal grief rituals: An analysis of symbolic objects and actions. Death Studies 40, 9: 558-569.

13. Corina Sas, Steve Whittaker, Steven Dow, Jodi Forlizzi, and John Zimmerman. 2014. Generating implications for design through design research. Proc. Conference on Human Factors in Computing Systems, 1971-1980.

14. Chris D Shaw, Diane Gromala, and A Fleming Seay. 2007. The Meditation Chamber: Enacting Autonomic Senses. Proc. of ENACTIVE/07, 405-408.

15. Stoyan R Stoyanov, Leanne Hides, David J Kavanagh, Oksana Zelenko, Dian Tjondronegoro, and Madhavan Mani. 2015. Mobile App Rating Scale: A New Tool for Assessing the Quality of Health Mobile Apps. JMIR mHealth and uHealth 3, 1: e27.

16. Barbara Tomasino, Alberto Chiesa, and Franco Fabbro. 2014. Disentangling the neural mechanisms involved in Hinduism- and Buddhism-related meditations. Brain and Cognition 90: 32-40.

17. Jay Vidyarthi, Bernhard E. Riecke, and Diane Gromala. 2012. Sonic Cradle. Proc. Designing Interactive Systems Conference, 408-417. 